International Journal of Engineering \& Technology, 7 (3.17) (2018) 100-103
International Journal of Engineering \& Technology
SPC
Website: www.sciencepubco.com/index.php/IJET
Research paper

\title{
Contact Force and Dynamic Behavior of Automobile Wiper Blade System
}

\author{
I. Salleh ${ }^{1 *}$, M. Z. Md Zain ${ }^{1}$ and A. R. Abu Bakar ${ }^{2}$ \\ ${ }^{1}$ Department of Control and Design \\ ${ }^{2}$ Department of Automotive Engineering \\ Faculty of Mechanical Engineering \\ Universiti Teknologi Malaysia \\ 81310 Skudai, Johor \\ *Corresponding author Email: ismasyariff@gmail.com
}

\begin{abstract}
Windscreen wiper vibration problem is now becoming one of the comforts and safety concerns because it can be annoying to the driver and passengers and also affect concentration of the driver while driving. This paper investigate the problems by measuring the wiper blade contact force and vibration level on laboratory wiper experimental rig and wiper system on two different sedan passenger cars operated similarly. In order to measure the vibration and contact force along the wiper blade, MMA7660 accelerometer and a thin film force sensor FSR was used. The contact force is measured at four points; Points 1 (inner tip), 2 (middle blade) and 3 (middle blade) and Point 4 (outer tip), along the wiper blade. Based on the measurement, it was found that the contact force is much higher at Points 1 , Point 2 and Point 3 compared to Point 4. For vibration level, higher vibration is occurred at Points 2 and Point 3 . It can be conclude that the bigger the contact force value act on windscreen the bigger for the vibration level to be produce. From this founding, further research can be conducted and tackle the problem at certain point along the wiper blade.
\end{abstract}

Keywords: Wiper Blade; Dynamic Behavior; Contact Force.

\section{Introduction}

Wiper plays a significant role for vehicles by sweeping out rain, fog, dirt and other contaminants that stick on the windscreen. Conventional wiper system consist two blades for front wiper system as it attached at driver and passenger's side, a DC electric motor to provide power and a linkage mechanism to convert rotational movement from the motor into back and forth motion of the wiper arms as shown in Figure-1. The arm was pivoted at one end with a long rubber blade attached to it. The rubber blade will drains the water off or to smooth the water on the surface of windscreen to form a thin layer of water that allows light to pass through it without refracting or bending to assists driver visibility during driving especially in raining condition. Typical wiper blade operate in three conditions; on the dry glass (without water), wet glass (lubricate by water) and tacky condition (transitory regime between wet and dry) [1]. Two synchronized radial type arms usually used in common vehicle, but there were certain commercial vehicle applied one or more pantograph arm for its wiper system. Wiper needs maintenance and the blade must be replaced regularly. Streaking, jumping and uneven blade pressure on the windscreen was several symptoms of wiper deterioration that shows during its operation.

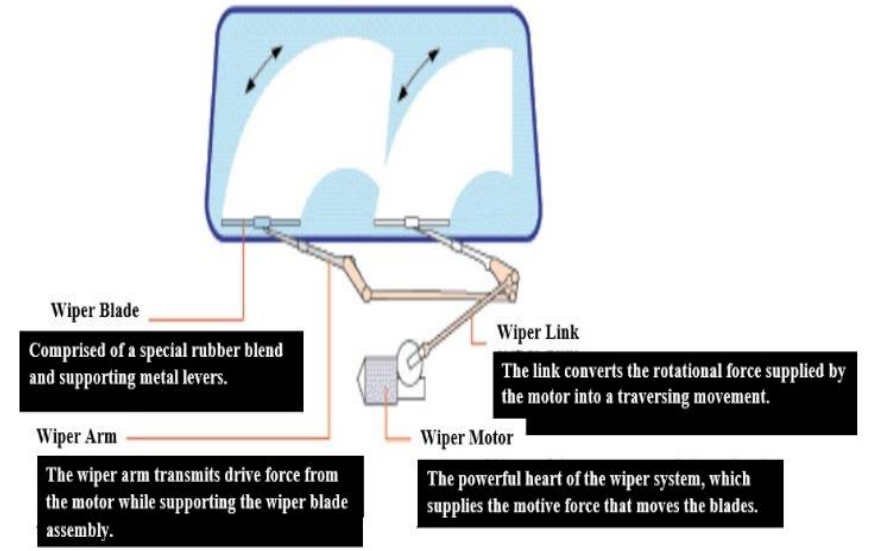

Fig. 1: Wiper system operation [2]

Noise and vibration reduction is a critical problem related to automotive industry especially in wiper system. The undesirable noise cause by vibration can annoying the driver and passengers and lead to wiper deterioration. Therefore, wiper noise and vibration reduction is needed for comfortable and safety purposes. Unfortunately, it is very often wiper blade generates vibration during its operation that affects the visibility of the driver and passengers and at the same time annoy them [3]. Noise and vibration has a close relationship as the vibration getting higher, the noise will also increase. The noise and vibration from the wiper system comes from two sources. First is the wiper motor (hidden part) and second is the wiper blade (visible part) [4]. These noises can be 
divided into three categories which are squeal, chattering and reversal noise. Squeal or squeaky noise is a high frequency noise generated at about $1000 \mathrm{~Hz}$. Meanwhile, reversal noise, a midfrequency noise is produces at about $500 \mathrm{~Hz}$ [5]. Lastly, the lowfrequency noise, chattering noise generated at $100 \mathrm{~Hz}$ [6]. The noise that was induced by friction between windscreen and the wiper blade can also be classified into wiping and reversal noise as clarified by Zhang, L [7]. From his research, wiping noise is a wide frequency noise with some harmonic squeal noise and reversal noise is a transient impulse noise. Glass wetness affects the wiping and reversal noise mainly as noise level under wet condition and half-dry condition are higher than under dry condition. Surprisingly, wiping speed give less effect to the noise. Vibration also can generated in the wiper system at certain wiping speed called chaotic or chatter vibration [8]. A non-uniform water film on the windscreen may disturb contact between the rubber blade and the windscreen interfaces that create vibration [9].

Dynamic analysis on the wiper is to enables efficiently determine the impact of time varying loads on the structural response of their product design to ensure performance, quality, and safety. Dynamic analysis on the wiper blade reversal behaviour using 2dimensional (2D) [10] and 3-dimensional (3D) [11], wiper model mainly focusing on the process to simulate blade reversal behaviour that give an idea to reduce the reversal noise and prevent reversal failure. There are several forces interact on the system such as internal force, inertia force, the gravity and carioles force, motor torque, and the reaction force which each blade receives from the windscreen. The extension analysis from 2D to 3D model is to enable calculation of dynamic reaction forces in vertical and frictional directions at any point within wiping area. The 3D analysis simulate reversal noise behaviour more accurate compared to $2 \mathrm{D}$ analysis done previously [11]. Based on experiment to clarify the dynamic behaviour of the wiper blade during reversal motion, the cross sectional model of the blade rubber shows that during reversal, the tip of the blade is in the rest state on the swept surface for a finite time and the angle of the blade changes continuously from negative to positive during the rest state of the tip [12]. This paper presents an experimental investigation of the contact force and vibration on front windscreen wiper system. These problem bring annoyance to the driver and passengers as it can affect comfort-ness and concentration during driving. The experiment used three different windscreen wiper setups. Four points along the wiper blade are selected as measurement point for contact force and vibration. Higher contact force can leads to higher vibration. The middle location of the wiper blade would produce higher contact than at the wiper tip since the wiper arm holds the blade at the centre. These experiment is to determine the critical location of vibration along the wiper and compare the similarity of vibration behaviour of experimental rig with wiper system on car. The rig will be further used for the next test.

\section{Wiper Experimental Rig}

An experimental rig was built as a platform for this experiment and for further analysis on the wiper system noise and vibration. The rig must operate same as the wiper system install in the vehicle. It's an assembly of wiper system of passenger car and installed on the fabricated steel platform. Figure- 2 shows an assembly of front windscreen wiper system experimental rig that is used in this study. The operation of the wiper is controlled by the wiper controller where it can provide three different speed modes: slow $(8 \mathrm{rad} / \mathrm{s})$, intermediate ( $8 \mathrm{rad} / \mathrm{s}$ and 2 seconds interval) and fast (25 $\mathrm{rad} / \mathrm{s})$. The experimental rig is built in accordance with ISO 9259:1991 - Passenger cars- Windscreen wiper system -Wiper arm to blade connection standard.

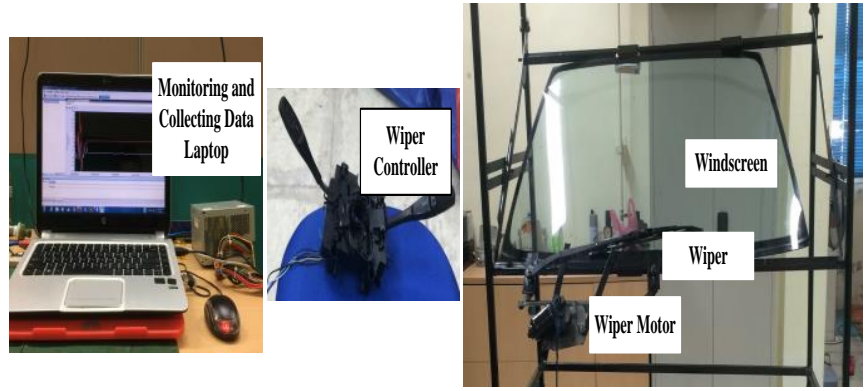

Fig. 2: Wiper system experimental rig

As mention earlier, in this experiment, the wiper is tested using three different wiper setups: i) Experimental rig, ii) car A and iii) car B and measured at four selected points along the rubber blade, Point 1, Point 4 (wiper tip), Point 2, Point 3 (middle blade), as shown in Figure-3. The details of windscreen wiper specification is shown in Table-1. By using the same type of wiper and hook, the differences only the windscreen angle and wiper size.

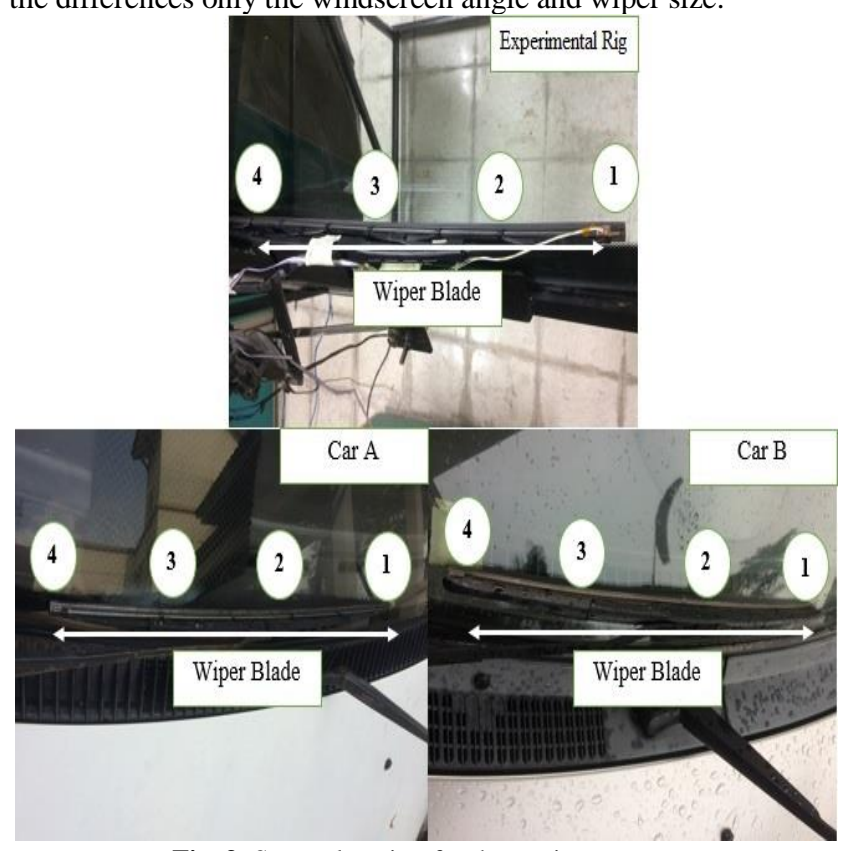

Fig. 3: Sensor location for three wiper system

\begin{tabular}{|c|c|c|c|c|c|}
\hline & Car & $\begin{array}{l}\text { Wiper } \\
\text { Type }\end{array}$ & $\begin{array}{c}\text { Windscreen } \\
\text { Angle }\end{array}$ & $\begin{array}{c}\text { Wiper } \\
\text { Size } \\
\text { (Right/Le- } \\
\mathrm{ft})\end{array}$ & $\begin{array}{c}\text { Hook } \\
\text { Type }\end{array}$ \\
\hline Rig & - & \multirow{3}{*}{$\begin{array}{l}\text { Uni- } \\
\text { lever }\end{array}$} & $30^{\circ}$ & $20 " / 17 "$ & \multirow{3}{*}{$\mathrm{U}$} \\
\hline $\begin{array}{c}\text { Car } \\
\text { A }\end{array}$ & $\begin{array}{l}1500 \mathrm{cc} \\
\text { (M) }\end{array}$ & & $30^{\circ}$ & $20 " / 17 "$ & \\
\hline $\begin{array}{c}\text { Car } \\
\text { B }\end{array}$ & $\begin{array}{c}850 \mathrm{cc} \\
(\mathrm{M})\end{array}$ & & $29^{\circ}$ & $18 " / 16 "$ & \\
\hline
\end{tabular}

\section{Wiper Contact Force, Noise and Vibration Measurement}

In order to measure contact force between wiper blade and windscreen, a thin layer force sensor FSR is used (see Figure-4B). A simple Arduino computer programme was developed and uploaded into Arduino micro-controller to control the force sensor and monitored the reading from the sensor. Figure-5 shows the integration of force measurement as the sensor is place under the wiper blade that stick on the windscreen.

Vibration on the wiper system is measured by using a pair of MMA7660 accelerometer single axis (see Figure-4A) and the data was processed by ADVANTECH USB-4716: Portable Data Acquisition Module. The accelerometer was attached at selected 
points at the wiper blade as given in Figure-3. The accelerometer was calibrated using Kristle Type 8921 calibrator. The wiper will be operated at intermittent operation level and the measurement is conducted at dry windscreen. Sample frequency is set at $100 \mathrm{sec}-$ ond per sample.

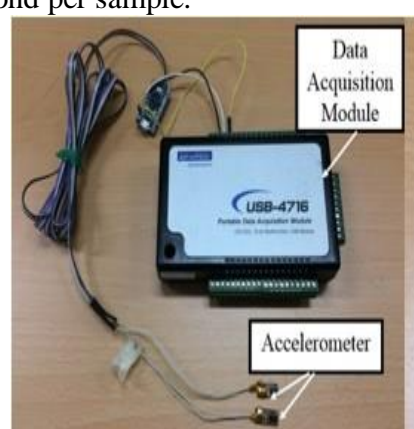

(a) MMA 7660 Accelerometer

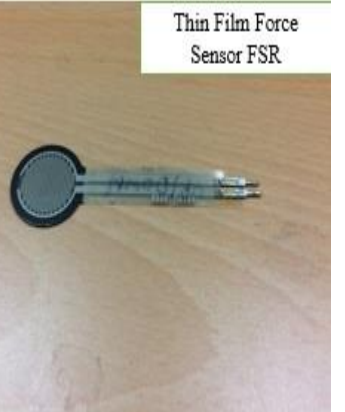

(b) FSR Force Sensor

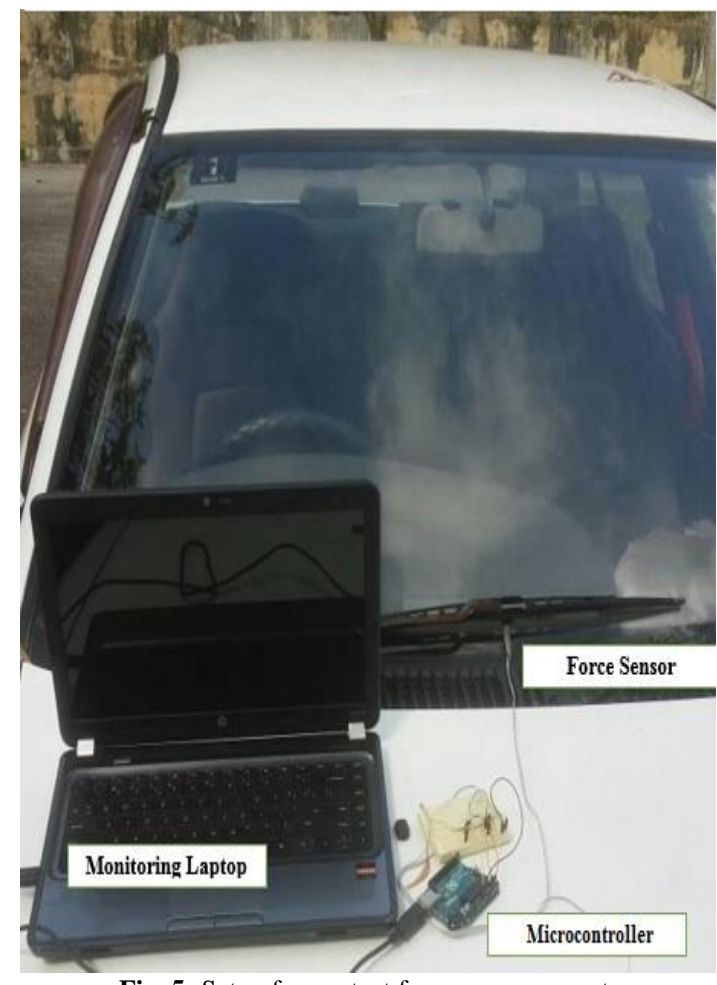

Fig. 5: Setup for contact force measurement.

\section{Results and Discussion}

Once finish with contact force measurement, the force data that were recorded is presented in term of average force acting on the windscreen. Figure- 6 shows the comparison graph of average contact force at four measurement point. Based on the graph the contact force is much smaller at the inner and outer tip of the rubber blade (Point 1 and Point 4) compared to the contact force at the middle of the blade (Point 2 and Point 3). At Point 1 (inner tip), wiper blade contact force for experimental rig and Car A almost the same compare to Car B with the value of $0.0175 \mathrm{~N}, 0.0173 \mathrm{~N}$ and $0.012 \mathrm{~N} . \mathrm{m} / \mathrm{A} . \mathrm{s}$ respectively. At Point 2 (middle), the pattern is different with force for Car $\mathrm{A}$ is much higher compare to wiper rig and Car B with the value of $0.024,0.019$ and $0.015 \mathrm{~N} . \mathrm{m} / \mathrm{A} . \mathrm{s} / \mathrm{The}$ contact force is higher at for wiper rig compare to Car A and Car $\mathrm{B}$ at Point 3 (middle) with the value of $0.0334,0.0223$ and 0.0207N.m/A.s. Lastly, at Point 4 (Outer tip), a drastic reduction of force can be seen with the value is almost the same for the rig and Car A at 0.0063 N.m/A.s and 0.0071N.m/A.s for Car B. So, the contact force for wiper experimental rig is almost the same as Car A and Car B at point 1, 2 and 4 but much higher compared to Car A and Car B at point 3. This indicate the rig produce the same force and can be used as wiper platform for wiper analysis in the future.

The force distribution along the rubber blade is important to give a good wiping quality for the windscreen. There are few reasons for un-similarity values of contact force between three wiper system setups. One of the reasons is the surrounding conditions during the measurement was neglected. The measurement was done at different places. For wiper experimental rig, the measurement was done in the room with room temperature whereas the measurement for Car A and Car B is taken place at parking lot with average surrounding temperature is in the range of $30-35$ degree Celsius. The temperature of the surrounding may affect the reading as the windscreen for Car A and Car B is exposed to the slightly higher temperature compare to windscreen for wiper experimental rig. The condition is neglected in this experiment because to focus on the similarity of range of vibration of the rig that will be used for the next test. There is different in the results but not significantly affected for the next test. The force between rubber blade and windscreen is expected to be different at each point. This is because of the curvature of the windscreen.

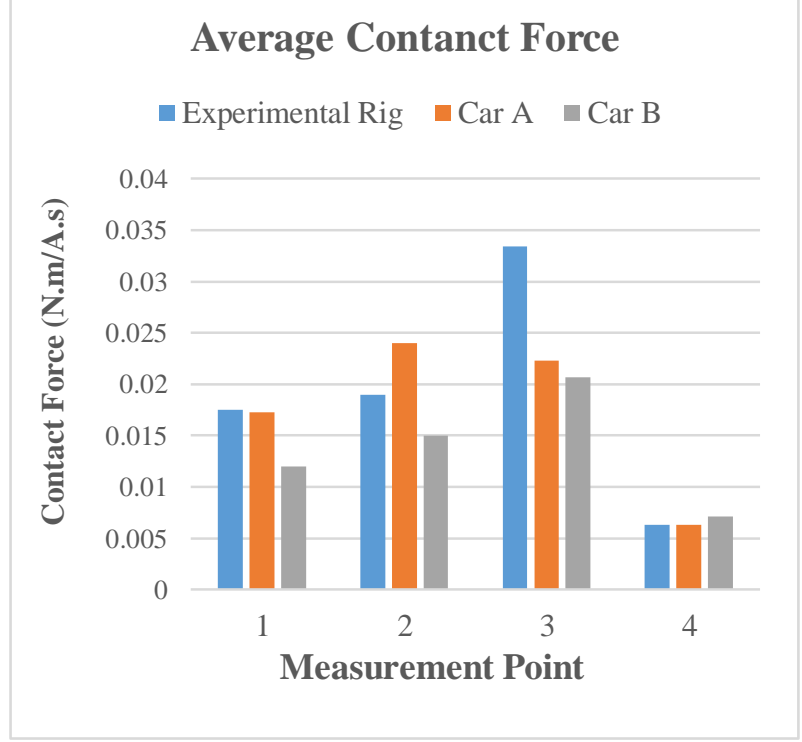

Fig. 6: Average of contact force.

The MMA 7760 accelerometer take the reading for vibration from the wiper during operation that connected to Data Acquisition Module. Figure-7 shows the frequency domain comparison graph between three different wiper systems according to measurement point. Based on the graph, the magnitude of the vibration for wiper experimental rig produced is less compare to wiper system for Car A and Car B. The vibration level for Car A looks dominant in four measurement point. This happen because the wiper blade for car A is not been maintain for a quite some time. So, during the measurement, the wiper start to shows deterioration in performance where streaking and jumping develop during wiping operation.

The highest frequency level for the experimental rig wiper blade lies in the frequency range below $50 \mathrm{~Hz}$, a low frequency noise or called chatter noise. The graph shows that at the tip of the wiper blade (Point 1 and Point 4), the tabulation of frequency level is less compared to the middle part (Point 2 and Point 3 ). This indicate noise and vibration is produce much higher at middle part. The streaking and jumping effect usually more visible at the middle of the rubber blade. 

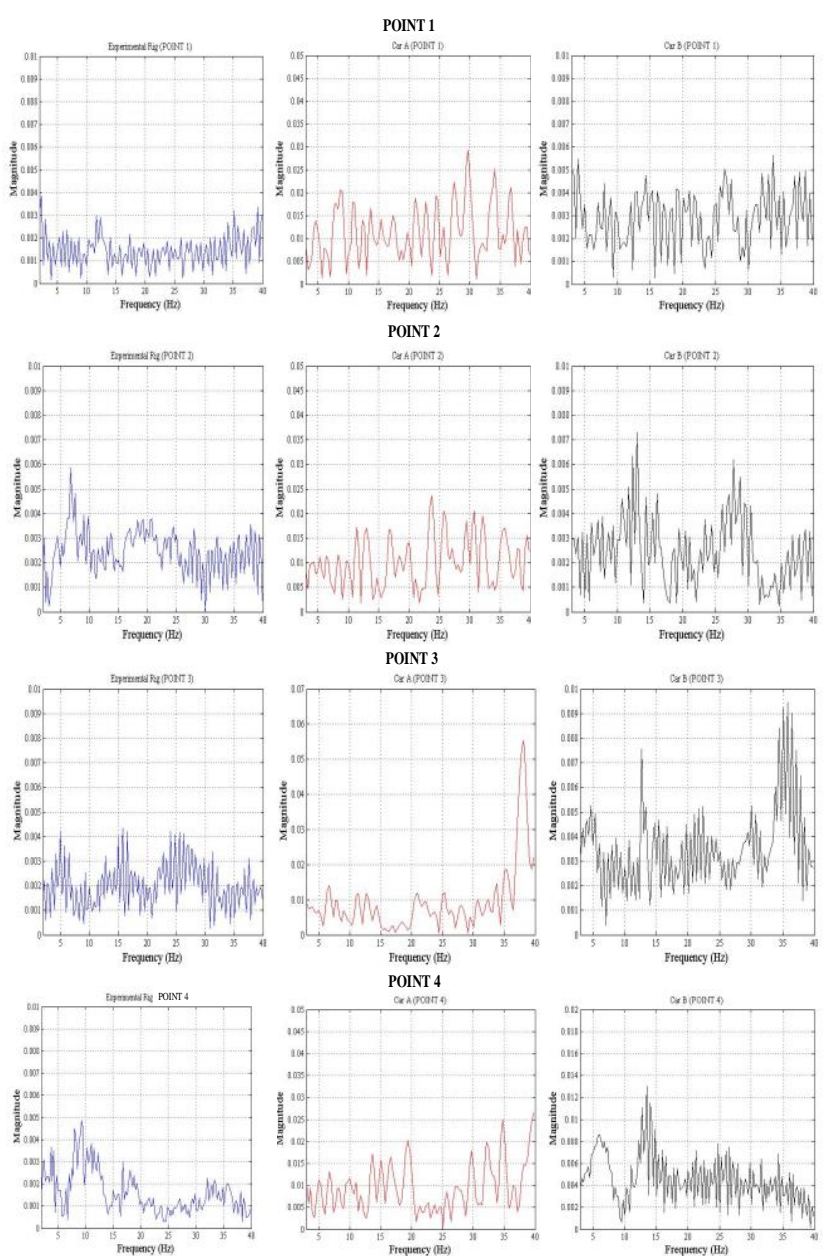

Fig. 7: Frequency domain graph for noise and vibration level

\section{Conclusion}

As conclusion, the measurement of noise and vibration and contact force between wiper rubber blade and windscreen was conducted to analyse the similarity and detect the location of the higher contact force that leads to higher vibration. Based on the vibration measurement, the magnitude for these three wiper system produce almost at the same range at four measurement point and the value for contact force along the blade is slightly different for these three wiper system but the range is still considerably low. The results shows that the middle part of wiper blade, which is Point 2 and Point 3, has generate much higher noise and vibration compared at Point 1 and Point 4. Same for the contact force where much higher force generate at Point 2 and Point 4. This indicate that higher contact force can lead to higher vibration level for wiper blade. For future study, an analysis can be conducted especially at the middle part of wiper blade as more force focusing on the middle. The effect of spring tension on the contact force of the wiper blade can also be investigate.

\section{Acknowledgement}

The authors would like to send gratitude to Universiti Teknologi Malaysia (UTM) and also to Ministry of Education for providing support especially in financial for my study under MyBrain program.

\section{References}

[1] A. Koenen and A. Sanon, Oct. 2007. Tribological and vibroacoustic behavior of a contact between rubber and glass (application to wiper blade). Tribol. Int., vol. 40, no. 10-12, pp. 1484-1491..

[2] Denso. 2008. Wiper Technical Information. Denso International Product Co. [Online]. Available: www.denso.sg/tpl/pdtlineup_wiper_technicalinfo.html. [Accessed: 24-Sep-2008].

[3] S. Goto, H. Takahashi and T. Oya. 2001. Clarification of the mechanism of wiper blade rubber squeal noise generation. JSAE Rev., vol. 22 , no. 1 , pp. 57-62.

[4] H. Idris. 2007. Study of Windshield Wiper Noise. Undergraduate Thesis of Universiti Teknolofi Malaysia.

[5] S. Goto, H. Takahashi and T. Oya. 2001. Investigation of Wiper Blade Squeal Noise Reduction Measures.

[6] R. Suzuki and K. Yasuda. 1998. Analysis of Chatter Vibration in an Automotive Wiper Assembly. JSME Int. J. Ser. C, vol. 41, no. 3, pp 616-620.

[7] L. Zhang. 2010. Experimental Investigation into Friction Induced Noise of Automotive Wiper System. SAE Tech. Pap. 2001-01-0749, vol. 2010, no. 1 .

[8] Z. Wang and K. T. Chau. 2009. Control of chaotic vibration in automotive wiper systems. Chaos, Solitons and Fractals, vol. 39, no. 1, pp. $168-181$

[9] A. Bakar, E. Jamaluddin and L. Yin. 2007. An experimental investigation into noise and vibration of an automotive wiper. Regional Conference on Noise, Vibration and Comfort (NVC). pp. 261-269.

[10] S. Okura, T. Sekiguchi and T. Oya. 2000. Dynamic Analysis of Blade Reversal Behavior in a Windshield Wiper System. SAE Technical Paper 2000-01-0127.

[11] S. Okura and T. Oya. 2003. Complete 3D dynamic analysis of blade reversal behavior in a windshield wiper system. SAE Trans., no. 724 .

[12] M. Sugita, H. Yabuno and D. Yanagisawa. 2012. Bifurcation phenomena of the reversal behavior of an automobile wiper blade. Nonlinear Dyn., vol. 69, no. 3, pp. 1111-1123. 